\title{
Low Dose Radiation Therapy
}

National Cancer Institute

\section{Source}

National Cancer Institute. Low Dose Radiation Therapy. NCI Thesaurus. Code C15811.

Radiotherapy using radioactive particles that deposit a low amount of energy by radiation per unit leng th of travel. 